\title{
Hurricane Katrina: A Case Study of its Impacts on Medical Service Providers and Their Client Populations*
}

\author{
David A. Swanson*
}

Department of Sociology, University of California, Riverside, USA

\begin{abstract}
There is a great deal of literature in the areas of: (1) medical demography; (2) the effect of disasters on first responders; (3) measuring the immediate demographic and social effects of a disaster; and (4) the short and long term economic and financial effects of disasters. However, there is very little if anything about the demographic effects of large scale disasters on medical providers once rescue operations have been completed and operations move into the relief and recovery/rehabilitation phases associated with a disaster. This paper seeks to bridge this gap by providing as a "recovery/rehabilitation" case study, estimates of the effects of Hurricane Katrina on the client populations and candidates for a specific medical procedure in the service areas associated with two medical facilities on the Mississippi gulf coast. The estimates presented here show that Katrina had a substantial demographic impact and that this translated into an adverse impact on the client base of both medical facilities. Although the results come from a single case study, the results suggest that the effects of a disaster can have substantial impacts on medical care providers and their ability to continue business that goes well beyond physical damage. That is, these results suggest that the impact of demographic effects of a disaster on a client base can be more important than physical damage, a fact that does not appears to be widely recognized. The first step in effectively dealing with a disaster is the presence of a plan and it is typical of organizations to have both "disaster recovery" plans and "business continuation" plans. Given the long term effects of Katrina on client populations found in this case study, it would be prudent that medical care providers include estimates of demographic impacts on their client populations in these plans, particularly in regard to the long-term "effects horizon" of a given disaster
\end{abstract}

\section{INTRODUCTION}

There is a great literature in the areas of: (1) medical demography [1-12]; (2) the effects of disasters on first responders [13] ; (3) Measuring the immediate demographic and social effects of a disaster [14-18]; and (4) the short- and long-term economic and financial effects of disasters [19]. However, there is virtually nothing in the literature about the demographic effects of large scale disasters on medical providers once the rescue attempts have ended and operations move into the relief and recovery/rehabilitation phases associated with a disaster. There are several reasons why this knowledge gap needs to be filled in: First, medical providers themselves should be prepared to deal with the adverse affects of a disaster not only on their physical structures and staff, but also on the client populations they serve; second, recovery agencies need to understand that the loss of client populations represents a major problem to medical care providers that has not been adequately addressed; and third, accountants, litigators, financial planners, and actuaries need to be cognizant of these effects in advance of major disasters, which suggests that more research needs to be done in this area by medical sociologists and demographers.

*Address correspondence to this author at the Department of Sociology, University of California, Riverside, USA; Tel: 951827 4373; Fax: 951827 3000; E-mail: David.swanson@ucr.edu
This paper seeks to start to bridge this gap by providing as a case study, estimates of the effects of Hurricane Katrina on "recovery/rehabilitation phase" populations and medical procedure candidates in the service areas (defined by zip codes) associated with two medical facilities in the area of Biloxi, Mississippi, USA.

While this paper is only a single case study, it provides an illustration of the impact that a major disaster can have on the client base of a medical provider. The estimates presented here show that Katrina had a substantial demographic impact, which in turn impacted the client base underlying both medical facilities. As such, the results suggest that the effects of a disaster can have substantial impacts on medical care providers and their ability to continue business.

It is worthwhile to use Hurricane Katrina as a case study for at least three reasons. First, while relatively recent, sufficient time as gone by since it struck the Mississippi Gulf Coast on August $29^{\text {th }}, 2005$ for affected areas to have moved into the recovery phase. Second, data were collected after Katrina's impact that used US Census Bureau procedures and definitions, which allow for estimates to be generated that are consistent with census and related data. One effect of this is that population data can be generated that reflect the impact of Katrina and what would have been expected in the absence of Katrina. Third, as noted by Swanson et al. [18], the landfall of Hurricane Katrina on the Gulf Coast represented the greatest natural disaster in American history: at least 1,836 people lost their lives from Katrina; hundreds of 
Table 1. The Estimated 2007 Population of Service Area 1 by Age and Sex

\begin{tabular}{|c|c|c|c|c|}
\hline \multicolumn{5}{|c|}{ SERVICE AREA 12007 POPULATION B Y AGE \& SEX } \\
\hline & 2007 & 2007 & 2007 & 2007 \\
\hline $\begin{array}{l}\text { SEX \& AGE } \\
\text { GROUP }\end{array}$ & Zipcode 1 & Zipcode 2 & Zipcode 3 & TOTAL \\
\hline v 2_4 & 798 & 101,363 & 2441 & 3,621 \\
\hline v 4_9 & 663 & 1,344 & 474 & 3,483 \\
\hline v 12_14 & 674 & 1,314 & 641 & 3,632 \\
\hline v 14_19 & 971 & 1,343 & 497 & 3,731 \\
\hline v 32_34 & 1,117 & 1,136 & 393 & 3,636 \\
\hline v 34_39 & 816 & 1,383 & 427 & 3,424 \\
\hline v 32_34 & 773 & 1,423 & 416 & 3,793 \\
\hline v 34_39 & 679 & 1,384 & 433 & 3,496 \\
\hline v 42_44 & 471 & 1,381 & 446 & 3,499 \\
\hline v 44_49 & 688 & 1,399 & 427 & 3,494 \\
\hline v 42_44 & 644 & 1,332 & 466 & 3,339 \\
\hline v 44_49 & 467 & 934 & 346 & 1,837 \\
\hline v 62_64 & 412 & 764 & 383 & 1,448 \\
\hline v 64_69 & 339 & 461 & 198 & 1,288 \\
\hline v 72_74 & 338 & 383 & 119 & 742 \\
\hline v 74_79 & 178 & 348 & 123 & 439 \\
\hline v 82_84 & 123 & 118 & 42 & 362 \\
\hline v 84ovr & 83 & 41 & 33 & 147 \\
\hline $2 \_4$ & 1,249 & 1,343 & 441 & 3,743 \\
\hline 4_9 & 1,269 & 1,363 & 446 & 3,788 \\
\hline _12_14 & 998 & 1,334 & 414 & 3,747 \\
\hline _14_19 & 992 & 1,343 & 478 & 3,713 \\
\hline 32_34 & 1,234 & 1,214 & 424 & 3,443 \\
\hline 34_39 & 1,247 & 1,369 & 443 & 3,868 \\
\hline 32_34 & 1,244 & 1,383 & 446 & 3,893 \\
\hline 34_39 & 922 & 1,339 & 497 & 3,734 \\
\hline _42_44 & 726 & 1,333 & 419 & 3,449 \\
\hline 44_49 & 618 & 1,313 & 434 & 3,346 \\
\hline _42_44 & 448 & 1,337 & 436 & 3,322 \\
\hline _44_49 & 447 & 1,223 & 338 & 1,887 \\
\hline 62_64 & 468 & 864 & 343 & 1,674 \\
\hline 64_69 & 634 & 616 & 144 & 1,394 \\
\hline _72_74 & 494 & 449 & 137 & 1,282 \\
\hline _74_79 & 422 & 321 & 71 & 773 \\
\hline 82_84 & 324 & 193 & 41 & 437 \\
\hline $84 \mathrm{ovr}$ & 344 & 134 & 37 & 397 \\
\hline P2_4 & 1,847 & 3,624 & 893 & 4,343 \\
\hline P4_9 & 1,731 & 3,627 & 931 & 4,369 \\
\hline P12_14 & 1,673 & 3,442 & 1,144 & 4,377 \\
\hline P14_19 & 1,961 & 3,496 & 976 & 4,433 \\
\hline P32_34 & 3,141 & 3,141 & 797 & 4,289 \\
\hline P34_39 & 1,873 & 3,641 & 849 & 4,373 \\
\hline P32_34 & 1,837 & 3,884 & 973 & 4,684 \\
\hline P34_39 & 1,479 & 3,733 & 1,239 & 4,331 \\
\hline P42_44 & 1,377 & 3,724 & 1,266 & 4,247 \\
\hline P44_49 & 1,326 & 3,713 & 933 & 4,941 \\
\hline P42_44 & 1,193 & 3,446 & 891 & 4,432 \\
\hline P44_49 & 1,114 & 1,936 & 684 & 3,734 \\
\hline P62_64 & 1,278 & 1,638 & 434 & 3,333 \\
\hline P64_69 & 943 & 1,177 & 343 & 3,483 \\
\hline P72_74 & 733 & 843 & 346 & 1,832 \\
\hline P74_79 & 478 & 449 & 173 & 1,322 \\
\hline P82_84 & 426 & 312 & 83 & 797 \\
\hline P84ovr & 337 & 176 & 42 & 444 \\
\hline AOAA9 & 33,616 & 34,138 & 13,624 & 71,348 \\
\hline POP 44+ & 4,189 & 6,628 & 3,113 & 13,911 \\
\hline POP 64+ & 3,996 & 3,244 & 924 & 6,944 \\
\hline
\end{tabular}

thousands of Gulf Coast residents lost their homes and jobs; and economic losses have been estimated at $\$ 81.2$ billion in
(2005 dollars), nearly double the costs associated with the next most costly disaster, Hurricane Andrew ( $\$ 45$ billion in 2005 dollars) and nine times more than Hurricane Camille (\$9 billion in 2005 dollars).

The case study is presented in two parts. The first examines the demographic effects of Hurricane Katrina on two service areas associated with a medical provider and the second part consists of an examination on the effects of Hurricane Katrina on the candidates for a specific medical procedure from these two service areas. The report concludes with a discussion of the effects on both population and the candidates as an illustration of the broader effects that a major disaster can have on the ability of medical service providers to continue business. The appendix documents the data and methods used in the study.

Before proceeding on to the results, it is worthwhile to note here what is meant by the post-disaster phases of rescue, relief, and recovery/rehabilitation. The definitions provided by the Asian Disaster Reduction Center [20] are used for this purpose.

The rescue phase usually consists of a forty-eight period immediately following a disaster in which local people and trained professionals attempt to save lives among the affected population. When rescue operations end, the relief phase begins in which food, water, clothing, medical supplies, shelters, and other elements associated with basic survival are delivered to the affected population. This phase usually lasts between one to three months. In the recovery/rehabilitation phase, social, economic and other infrastructures are restored and the economy revitalized. In the short term, debris clearing and removal usually takes place, while in the longer term, rebuilding is undertaken. This phase usually lasts for one to several years, but can be as long as five years.

\section{DEMOGRAPHIC EFFECTS OF KATRINA}

The examination of Katrina's demographic effects, proceeds by using 1990 and 2000 census data to develop "Cohort Change Ratios" [21] for the two service areas of the medical provider. These Cohort Change Ratios (CCRs) are then used to project the 2000 populations by age and sex forward to 2007. The projected population numbers are then adjusted using two sources: (1) data collected under the auspices of a study funded by the National Science Foundation [18]; and (2) special "Katrina estimates" done by the US Census Bureau [22]. These adjusted values form the 2007 "Katrina-impacted" populations (by age and sex) of the two service areas. To get an idea of the magnitude of population lost due to Katrina, these estimates are then compared to projections of the populations for these same two areas that were constructed by a well-established private sector data vendor in 2003, well in advance of Hurricane Katrina.

Table 1 provides the estimated "Katrina-impacted" population in 2007 of Service Area 1 by age and sex. Table 2 provides the estimated Katrina-impacted population in 2007 of Service Area 2 by age and sex.

In regard to the effects of Hurricane Katrina on the total population of Service Area 1 (Table 1), the total Katrinaimpacted population in 2007 is 68,465 . This is 10,246 less 
Table 2. The Estimated 2007 Population of Service Area 2 by Age and Sex

\begin{tabular}{|c|c|c|c|c|c|c|c|c|c|c|}
\hline \multicolumn{10}{|c|}{ SERVICE AREA 22007 POPULATIO\& B Y AGE A\&D SEX } & \multirow[b]{2}{*}{ TOTAL } \\
\hline SEX \& AGE GROUP & Zipcode 4 & Zipcode 5 & Zipcode 6 & Zipcode 7 & Zipcode 8 & Zipcode 9 & Zipcode 10 & Zipcode 11 & Zipcode 12 & \\
\hline r 2_4 & 433 & 618 & 347 & 648 & 828 & 464 & 164 & 311 & 343 & 4,147 \\
\hline r 4_9 & 474 & 647 & 146 & 468 & 788 & 637 & 174 & 331 & 374 & 3,941 \\
\hline r 12_14 & 481 & 733 & 337 & 467 & 863 & 642 & 181 & 344 & 376 & 4,323 \\
\hline r 14_19 & 416 & 644 & 349 & 491 & 974 & 619 & 143 & 394 & 367 & 4,317 \\
\hline r 32_34 & 643 & 487 & 133 & 643 & 647 & 439 & 133 & 343 & 314 & 3,693 \\
\hline r 34_39 & 664 & 423 & 313 & 766 & 693 & 414 & 133 & 183 & 324 & 3,873 \\
\hline r 32_34 & 447 & 483 & 319 & 613 & 844 & 429 & 146 & 317 & 337 & 3,934 \\
\hline r 34_39 & 482 & 714 & 331 & 624 & 869 & 461 & 149 & 341 & 347 & 4,396 \\
\hline r 42_44 & 442 & 737 & 342 & 414 & 939 & 488 & 177 & 329 & 332 & 4,364 \\
\hline r 44_49 & 486 & 821 & 418 & 479 & 1,263 & 449 & 184 & 333 & 343 & 4,673 \\
\hline r 42_44 & 491 & 933 & 426 & 486 & 931 & 496 & 194 & 334 & 342 & 4,621 \\
\hline r 44_49 & 444 & 773 & 341 & 429 & 739 & 443 & 172 & 323 & 341 & 3,781 \\
\hline r 62_64 & 421 & 647 & 494 & 383 & 624 & 422 & 144 & 179 & 192 & 3,464 \\
\hline r 64_69 & 389 & 433 & 338 & 336 & 443 & 316 & 111 & 137 & 163 & 3,444 \\
\hline r 72_74 & 376 & 348 & 324 & 192 & 334 & 342 & 83 & 84 & 113 & 1,974 \\
\hline r 74_79 & 332 & 312 & 322 & 173 & 333 & 161 & 49 & 42 & 74 & 1,383 \\
\hline r 82_84 & 136 & 134 & 126 & 128 & 93 & 97 & 32 & 39 & 41 & 774 \\
\hline r 84ovr & 98 & 84 & 124 & 84 & 66 & 48 & 17 & 8 & 34 & 433 \\
\hline $2 \_4$ & 468 & 474 & 336 & 637 & 733 & 436 & 182 & 326 & 343 & 3,823 \\
\hline _4_9 & 493 & 493 & 187 & 432 & 774 & 484 & 148 & 183 & 334 & 3,717 \\
\hline _12_14 & 488 & 648 & 323 & 478 & 847 & 644 & 164 & 333 & 378 & 4,126 \\
\hline _14_19 & 481 & 614 & 332 & 464 & 793 & 623 & 169 & 323 & 377 & 4,233 \\
\hline 32_34 & 487 & 413 & 143 & 746 & 644 & 433 & 136 & 337 & 347 & 3,796 \\
\hline 34_39 & 672 & 466 & 382 & 694 & 833 & 491 & 166 & 174 & 334 & 4,128 \\
\hline 32_34 & 434 & 487 & 373 & 642 & 826 & 629 & 146 & 199 & 313 & 4,228 \\
\hline 34_39 & 498 & 684 & 326 & 444 & 944 & 644 & 163 & 333 & 374 & 4,421 \\
\hline _42_44 & 444 & 722 & 424 & 423 & 943 & 633 & 178 & 313 & 331 & 4,338 \\
\hline _44_49 & 624 & 847 & 427 & 443 & 1,232 & 622 & 193 & 334 & 384 & 4,743 \\
\hline _42_44 & 488 & 844 & 479 & 469 & 884 & 614 & 193 & 334 & 338 & 4,444 \\
\hline _44_49 & 434 & 736 & 464 & 418 & 744 & 492 & 173 & 318 & 341 & 4,227 \\
\hline 62_64 & 464 & 727 & 443 & 349 & 641 & 486 & 144 & 163 & 189 & 3,617 \\
\hline 64_69 & 366 & 493 & 387 & 377 & 494 & 346 & 132 & 132 & 164 & 3,769 \\
\hline 72_74 & 343 & 348 & 312 & 334 & 386 & 329 & 89 & 83 & 116 & 3,338 \\
\hline _74_79 & 388 & 363 & 194 & 338 & 344 & 333 & 73 & 63 & 99 & 1,684 \\
\hline -82_84 & 332 & 186 & 196 & 166 & 142 & 144 & 41 & 44 & 73 & 1,343 \\
\hline $84 \mathrm{ovr}$ & 146 & 198 & 174 & 144 & 134 & 131 & 43 & 38 & 77 & 1,266 \\
\hline P2_4 & 1,222 & 1,193 & 493 & 1,374 & 1,442 & 1,291 & 344 & 417 & 494 & 7,949 \\
\hline P4_9 & 968 & 1,342 & 343 & 1,288 & 1,464 & 1,311 & 333 & 414 & 429 & 7,648 \\
\hline P12_14 & 969 & 1,382 & 632 & 946 & 1,732 & 1,384 & 346 & 478 & 444 & 8,329 \\
\hline P14_19 & 997 & 1,369 & 668 & 947 & 1,766 & 1,333 & 331 & 496 & 444 & 8,342 \\
\hline P32_34 & 1,342 & 999 & 376 & 1,429 & 1,323 & 1,243 & 369 & 482 & 463 & 7,489 \\
\hline P34_39 & 1,334 & 1,269 & 491 & 1,463 & 1,434 & 1,224 & 398 & 347 & 439 & 7,981 \\
\hline P32_34 & 1,283 & 1,169 & 493 & 1,343 & 1,661 & 1,117 & 323 & 417 & 442 & 7,933 \\
\hline P34_39 & 1,178 & 1,399 & 637 & 1,149 & 1,833 & 1,326 & 311 & 464 & 431 & 8,697 \\
\hline P42_44 & 1,286 & 1,437 & 744 & 1,217 & 1,883 & 1,332 & 346 & 431 & 443 & 8,623 \\
\hline P44_49 & 1,189 & 1,648 & 834 & 1,133 & 3,283 & 1,149 & 376 & 468 & 437 & 9,436 \\
\hline P42_44 & 1,178 & 1,788 & 884 & 944 & 1,826 & 1,312 & 387 & 449 & 488 & 9,146 \\
\hline P44_49 & 978 & 1,427 & 816 & 837 & 1,473 & 943 & 343 & 432 & 483 & 7,789 \\
\hline P62_64 & 866 & 1,364 & 946 & 743 & 1,347 & 886 & 312 & 341 & 379 & 7,281 \\
\hline P64_69 & 644 & 1,236 & 714 & 413 & 939 & 663 & 331 & 347 & 337 & 4,313 \\
\hline P72_74 & 638 & 696 & 614 & 434 & 732 & 449 & 173 & 168 & 339 & 4,323 \\
\hline P74_79 & 428 & 473 & 394 & 413 & 478 & 384 & 133 & 113 & 174 & 3,266 \\
\hline P82_84 & 347 & 331 & 323 & 374 & 343 & 343 & 82 & 74 & 114 & 3,216 \\
\hline P84ovr & 344 & 383 & 379 & 337 & 321 & 169 & 49 & 36 & 121 & 1,499 \\
\hline AOAA9 & 16,448 & 32,372 & 12,643 & 16,272 & 33,972 & 16,632 & 4,949 & 6,347 & 7,338 & 133,494 \\
\hline Pop 44+ & 4,336 & 4,672 & 4,267 & 3,419 & 4,399 & 3,843 & 1,336 & 1,398 & 1,827 & 31,266 \\
\hline Pop 64+ & 3,393 & 3,798 & 3,324 & 1,841 & 3,479 & 3,214 & 674 & 637 & 946 & 16,196 \\
\hline
\end{tabular}

than the 2007 population of 78,711 projected in 2003 by the well-established private sector data vendor for this same area. Thus, Katrina is estimated to have reduced the total population of this area by 13 percent as of 2007, approximately two years after it struck. 


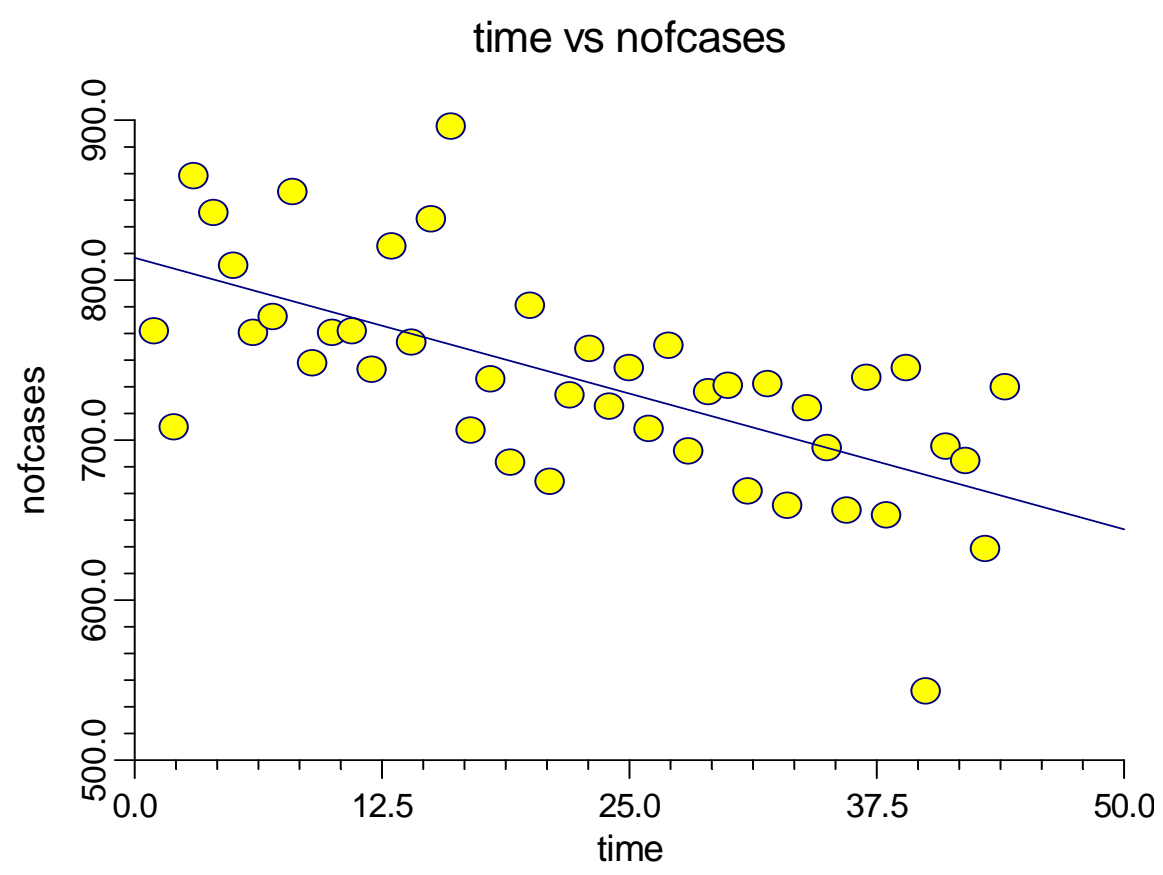

Fig. (1). The number of procedures performed at facility $x$ related to the pool of potential medical procedure patients in the two service areas.

For purposes of the second part of this study, candidates for the specific procedure examined in this case study, it is the population aged 55 years and over that represents the client population. In looking at those aged 55 years and over, there are 13,281 people in the Katrina-impacted estimate of this age group in Service Area 1 in 2007 (Table 1). This is 1,753 less than the $200755+$ population of 15,034 , which was projected in 2003 by the data vendor. Thus, Katrina is estimated to have reduced the population aged 55 years and over by 11.7 percent in Service Area 1 as of 2007.

For Service Area 2 (Table 2), the total "Katrinaimpacted" population in 2007 is 122,595 , which is 23,922 less than the 2007 population of 146,517 projected in 2003 by the data vendor for this same area. Thus, Katrina is estimated to have reduced the total population of this area by 16.3 percent as of 2007. In considering age group 55+ for Service Area 2, there are 31,066 people in the Katrinaimpacted estimate for 2007. This is 5,532 less than the 2007 projected $55+$ population of 36,598 by the data vendor for Service Area 2. Thus, Katrina is estimated to have reduced the population aged 55 years and over by 15.1 percent in Service Area 2 as of 2007.

\section{KATRINA'S EFFECTS ON A MEDICAL PROVIDER}

The data in Fig. (1) represent a monthly time series (January, 2004 through August, 2007) of transactions of diagnostic codes (ICD 9) that are associated with the pool of patients the two service areas who presented themselves for this procedure at the medical provider's site "X.". The number of cases by month is shown on the vertical (Y) axis, while on horizontal (X) axis of the exhibit, the months are shown as $0,1,2,3, \ldots, 43$, where " 0 " represents January, 2004, "1" represents February, 2004 and so on up to "43," which represents August, 2007. For purposes of formatting, the horizontal axis numbers go to "50." The point at which Hurricane Katrina struck is represented on the horizontal axis at number "19."

As can be seen from an examination of Fig. (1), there is a distinct break around the point on the horizontal axis that represents the time period in which Katrina stuck (August of 2005 is represented by where point 19 would be located, which appears between 12.5 and 25 as shown on the horizontal axis). Prior to September, 2005, Facility " $X$ " averaged 782.4 cases per month; after August, 2005, it averaged 700.38 cases per month. As revealed by a regression model in which the independent variable, "Katrina," is dummy coded (prior to September, $2005=0$; after August, $2005=1$ ), the effect of Katrina is shown to result in 82 fewer cases per month. This effect is substantive and statistically significant, where "n of monthly cases" $=782.4-82.025$ $*$ (Katrina), $\mathrm{r}^{2}=.39, \mathrm{p}<.001$, which indicates a moderately strong regression model that is not due to chance.

Another way to examine the effect of Katrina on this caseload at Facility " $\mathrm{X}$ " is to look the underlying trend of the monthly number of cases from January, 2004 to August, 2007. As is shown by the least squares regression trend line in Fig. (1), the monthly number of cases is declining. Further analysis (discussed in Endnote \# 1) reveals that this trend is statistically significant. That is, underlying the monthly variation in the number of cases over time, there is a declining trend in the number of cases at Facility "X." In summary, the analyses support the conclusion that the effect of Katrina was profound in that there are, on average, 82 fewer cases per month after Katrina and, moreover, that the number of monthly cases of this type at Facility " $\mathrm{X}$ " is likely to continue to decline into the foreseeable future.

The data on the candidates from the two service areas who presented themselves for the same medical procedure at 


\section{time vs nofcases}

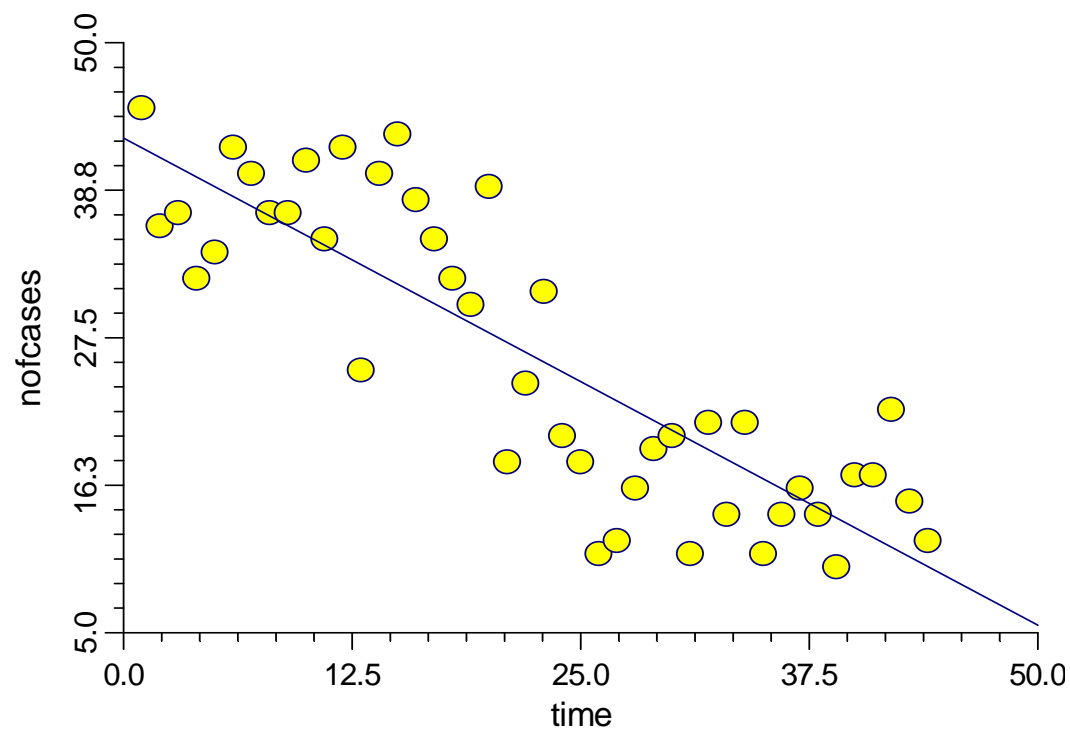

Fig. (2). The number of procedures performed at facility y related to the pool of potential medical procedure patients in the two service areas.

the medical provider's Facility "Y" are presented in Fig. (2). The number of cases is shown on the vertical axis and the time period (in months) is shown on the horizontal axis.

As is the case for the data presented in Fig. (1), the data in Fig. (2) represent a monthly time series (January, 2004 through August, 2007) of transactions of diagnostic codes (ICD 9) that are associated with the pool of patients who presented themselves for this procedure. As is the case for Facility "X" (Fig. 3), the data for Facility "Y" (Fig. 2) show a distinct break between the pre-Katrina months and the post-Katrina months: there is a distinct break around the point on the horizontal axis that represents the time period in which Katrina stuck (August of 2005 is represented by where point 19 would be located, which appears between 12.5 and 25 as shown on the horizontal axis). Prior to September, 2005, Facility "Y" averaged 37 cases per month; after August, 2005, it averaged 16.8 cases per month. As revealed by a regression model in which the independent variable, "Katrina," is dummy coded (prior to September, $2005=0$; after August, $2005=1$ ), the effect of Katrina is shown to result in 20 fewer cases per month. ${ }^{2}$ This effect is substantive and statistically significant, where "monthly $\mathrm{n}$ of cases" $=37-20.17 *($ Katrina $), \mathrm{r}^{2}=.81, \mathrm{p}<.001$, which indicates a strong regression model that is not due to chance.

The effect of Katrina on this caseload at Facility "Y," as can be seen by looking at the underlying trend of the monthly number of cases from January, 2004 to August, 2007, reveals a pattern similar to that found for these same types of cases in Facility "X." The least squares regression line in Fig. (2) shows that prior to the onset of Hurricane Katrina at the end of August 2005, the number of cases is distinctly higher than the time series subsequent to the onset of Katrina and that there is a declining trend in the number of cases at Facility "X." Again, this is supported by a statistically significant regression model (As described in Endnote \# 2). In summary, the analyses support the conclusion that the effect of Katrina on these types of cases at Facility "Y" was profound in that there are, on average, 20 fewer cases per month after Katrina and, moreover, that the monthly number of cases of this type at Facility "y" is likely to continue to decline into the foreseeable future.

\section{DEMOGRAPHIC EFFECTS AND MEDICAL PROVIDERS}

There is a high level of correspondence between the population data, especially the population aged 55+ (Tables 1 and 2) and the medical procedure data (Figs. 3 and $\mathbf{4}$ ) that show that Katrina had a measurable effect on the pool of patients who would present themselves for the medical procedure in the two service areas (primary and secondary) associated with facilities "X" and "Y." The effects can be quantified as follows:

(1) Prior to Katrina, at Facility "X," there was an average of 782 cases monthly associated with the pool of patients who would present themselves for the medical procedure; after Katrina, this number was reduced by $10 \%$ to approximately 700 . At Facility "Y," the Pre-Katrina monthly average of 37 of these types of cases was reduced by 55\% to approximately 17. Combined, these reductions come to about $13 \%$, from 819 to approximately 717 .

(2) The population from which these patients were drawn is largely in service areas 1 and 2. Katrina reduced the 2007 total population in these two areas by $15 \%$, from the expected number of 225,228 to the estimated number of 191,060. Katrina reduced the 2007 population $55+$ in these two areas by $13 \%$, from the expected number of 51,632 to the estimated number of 44,977 .

\section{SUMMARY}

Although this is a case study for a specific area, the estimates presented here suggest that at least in the case of 


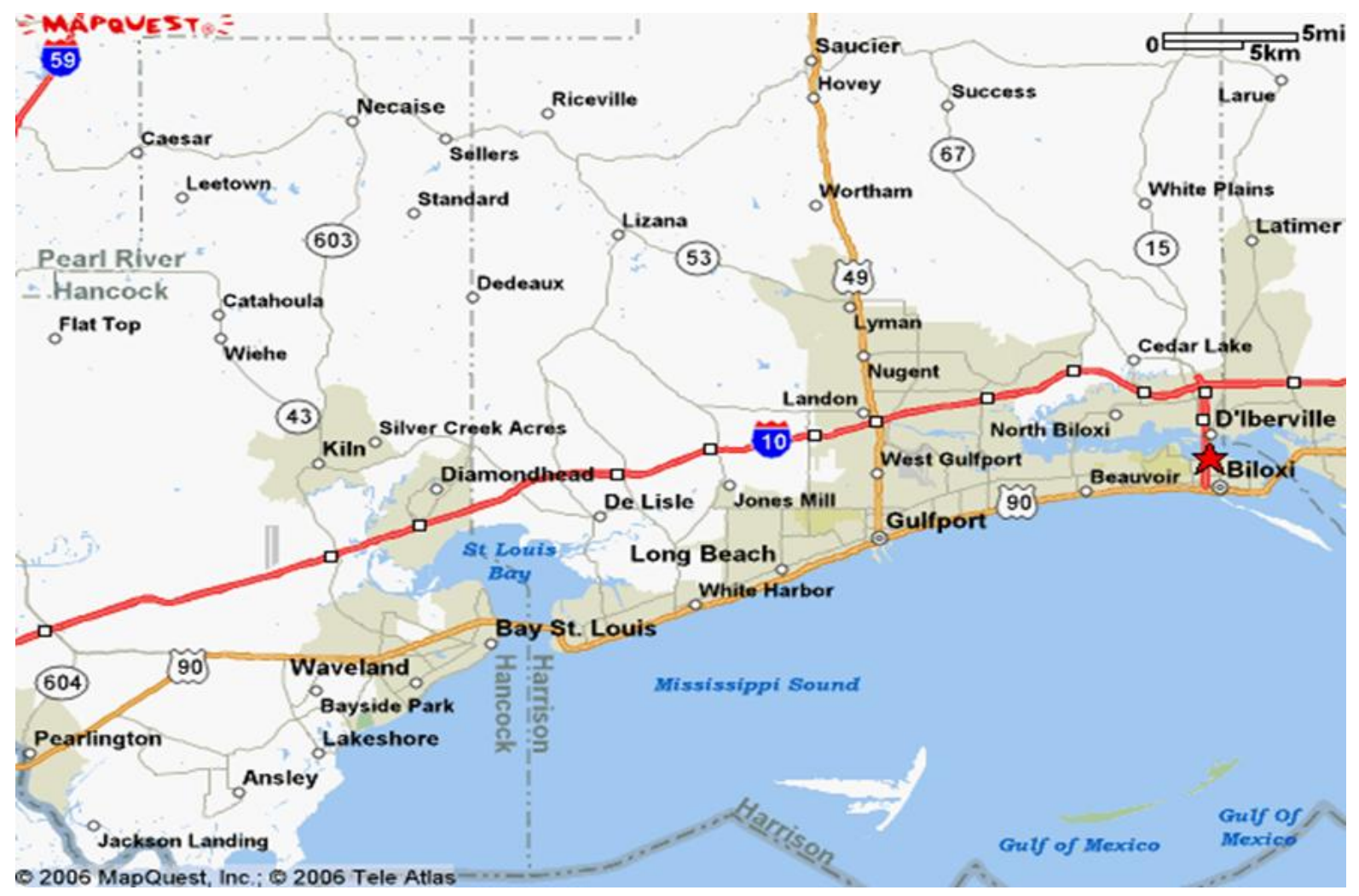

Fig. (3). The geographic context of the nsf study area.

Katrina's impact on the Mississippi gulf coast, the effects of a disaster can have substantial impacts on medical care providers not only during the relief and recovery phases, but well beyond them. The estimates presented here show that Katrina had a substantial demographic impact, which in turn impacted the client base underlying both of the medical facilities examined in this case study. As such, the results suggest that the effects of a disaster can have substantial impacts on medical care providers and their ability to continue business. In a broader look, Swanson [17] argues that the demographic effects of Hurricane Katrina on the Mississippi gulf coast will be long-lasting. In a similar vein, Cossman [23] finds that "agents of delay" have served to extend Katrina's effects on this same area and he argues that these same agents will be associated with future disasters, both natural and man-made.

The first step in effectively dealing with a disaster is the presence of a plan. As noted by Sokura and Cosby [24], it is typical of organizations to have both "disaster recovery" plans and "business continuation" plans. Given the long term demographic effects of Katrina that are suggested in this case study and estimated elsewhere [16, 17], it would seem that medical care providers at risk to large scale disasters should not only develop these types of plans, but to include in them, both estimates of both short and long-term demographic impacts.

In addition to disaster recovery and business continuation plans, the findings in this case study lead to three primary suggestions:

(1) medical providers themselves should be prepared to deal with the adverse affects of a disaster not only on their physical structures and staff, but also on the client populations they serve in terms of the entire disaster horizon;

(2) recovery agencies need to understand that the loss of client populations represents a major problem to medical care providers that has not been adequately addressed; and

(3) accountants, litigators, financial planners, and actuaries need to be cognizant of the fact that the loss of client populations are likely to have more of an impact on the business activities of medical providers than actual physical damage, which suggests that more research needs to be done in this area by medical sociologists and demographers.

\section{APPENDIX}

\section{Demographic Data and Methods}

The 2007 Katrina-impacted population estimates are based on data from three sources, PINEY BOWES MAPINFO, the US Census Bureau, and data collected under grant \#0555136 from the US National Science Foundation.

Pitney Bowes MAPINFO Data. MAPINFO (Now part of Pitney Bowes, Inc.) is an international corporation that provides demographic and related information for clients in the private and government sectors (http:// www.mapinfo.com/location/integration). One of the primary products of companies like MAPINFO is the provision of demographic information by zip code. For this project, Pitney Bowes MAPINFO provided 1990 and 2000 population data by age and sex for the 12 zip codes comprising the two service areas.

Census Bureau Data. In late 2006, the US Census Bureau [22] developed a set of special population 


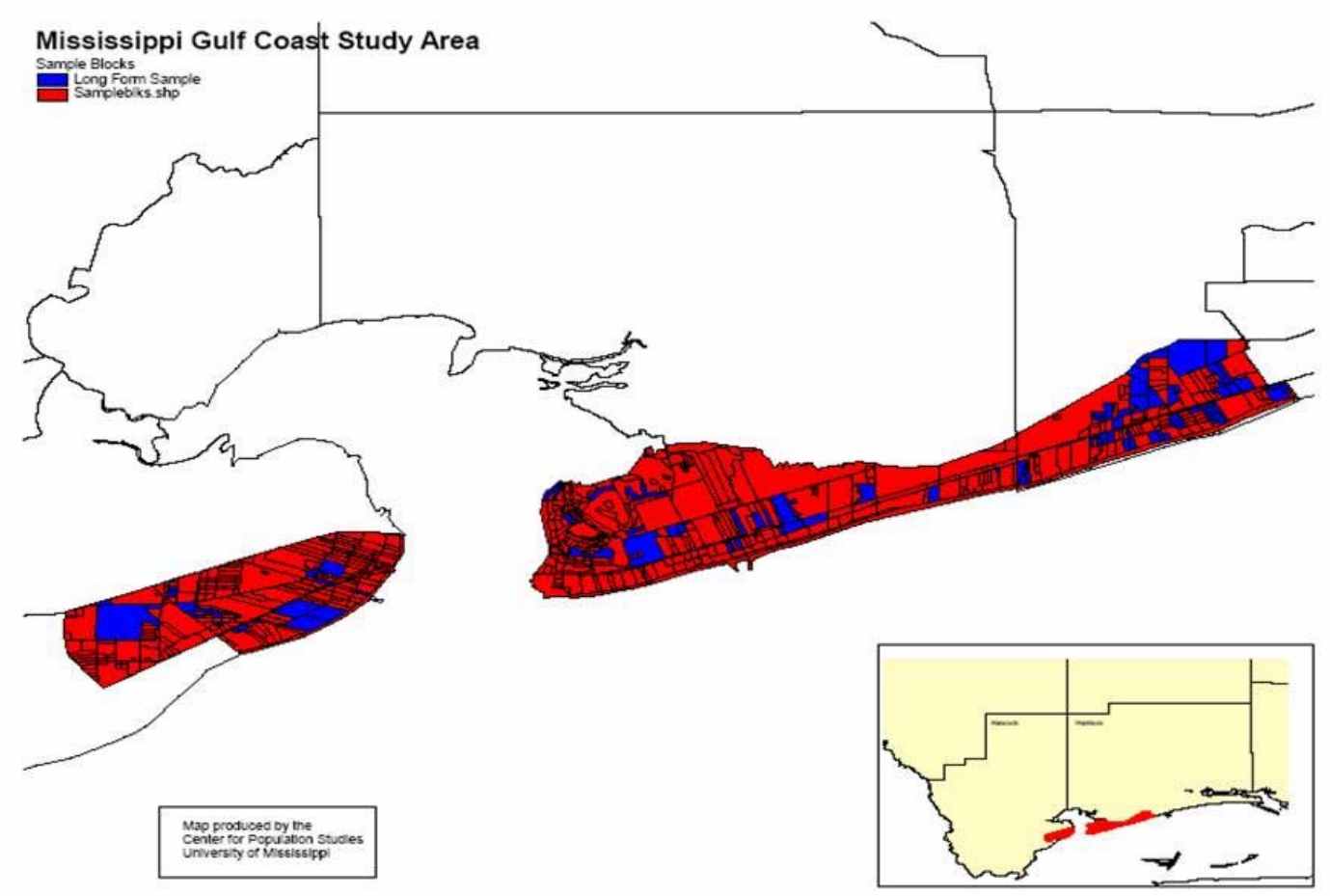

Fig. (4). The NSF study area and its target blocks.

estimates for counties impacted by Hurricane Katrina (http://www.census.gov/Press-Release/www/emergencies/ impacted_gulf_estimates.html). The January $1^{\text {st }}, 2006$ population estimate for Harrison County, Mississippi is 155,871 . In 2000, the population of Harrison County was determined by the US Census Bureau to be 189,601.

Data Collected under NSF Grant \# 0555136. The "census tract" level data used in this report to make adjustments to selected zip codes. For zip codes 39501, 39507, 39525, and 39560, data collected in census tracts 27 and 28, Harrison County, were used. For zip code 39520, data collected in census tracts 301 and 302, Hancock, County, were used. For zip code 39571, data collected in census tracts 39 and 30, Harrison County, were used. These census tract data were gathered under the auspices of one of nine post-Katrina research projects funded by the National Science Foundation under the provisions of the SGER program. ${ }^{3}$ Specifically, the data reported here are taken from work done by the recipients of SGER Grant \#0555136, which:

(1) gathered pre- and post-Katrina information on housing and population from 573 targeted census blocks at the epicenter of Katrina's impact on the Mississippi gulf coast that the 2000 census showed as containing people (the "Short Form"); and

(2) employed a random start, systematic selection, cluster sample targeting 126 of these 573 blocks for administration of a 115-item questionnaire (the "Long Form"), such that at least 350 completed questionnaires would be obtained. The Long Form was designed for several purposes, one of which was to collect retrospective information on the roles that social and kinship networks played in determining respondents' success (i.e., the capacity for respondents to sustain their physical and emotional well-being after Hurricane Katrina).

The geographic context of the Study Area for NSF SGER Grant \# 0555136 is provided in Fig. (3) and, the specific blocks are shown in Fig. (4). Full details of the data collection are found in Swanson et al. [18]. A brief description is as follows.

The primary data collection team included faculty and graduate students from the University of Mississippi, Mississippi State University, the University of Southern Mississippi, and the University of Tennessee Medical Center (Memphis), as well as several residents from the MS Gulf Coast. A secondary team was comprised of members of the geography division of the U.S. Census Bureau. This team geocoded selected sites and assisted with Short Form data collection. Collectively, the primary and secondary team members canvassed the Study Area to count and assess housing using a "Short Form" and to administer a "Long Form" Questionnaire. The team was successful in collecting Short Form data comprised of 10,547 completed surveys from 346 of the targeted 573 blocks and Long Form data comprised of 400 completed surveys from 71 blocks, 68 of which were from the 126 blocks targeted for Long Form data collection and three of which were from Short Form blocks erroneously canvassed.

The data collection process also captured information needed to provide a general assessment of survey data quality $[25,26]$. Using these criteria, the assessment suggested that the data are of good quality.

The Short Form contained identifying information (housing unit sequence number, block, tract, and as much information on a street address as possible) and captured 
four pieces of information: structure type (single or multiple unit dwelling, trailer, mobile home), whether it was permanent or temporary, its condition (habitable, heavily damaged, destroyed), and its occupancy status (occupied or vacant). The Short Form was approved for use by the Institutional Review Board of the University of Mississippi in the late fall of 2005. Short Form data were collected during two periods, January $8^{\text {th }}$ to $15^{\text {th }}, 2006$ and March $10^{\text {th }}$ to $19^{\text {th }}, 2006$, with the bulk of data being collected during the March $10^{\text {th }}$ to $19^{\text {th }}$ period.

The Short Form data $(\mathrm{N}=10,547)$ represent a complete enumeration of all housing in the 346 blocks, both permanent and temporary, as well as a determination of their condition (habitable, damaged, or destroyed) and occupancy status. These 346 blocks represent portions of two census tracts in Hancock County, MS (03010 and 03020) and four in Harrison County, MS (02700, 02800, 02900, \& 0300), areas that were at the epicenter of Katrina's Landfall in Mississippi.

Because census definitions and conventions were used, the Short Form (and the corresponding control sheets for the Long Forms in a given block) allow for a direct comparison of housing unit counts obtained in the study with Census 2000 housing unit counts on a block-by-block basis. From this, virtually all housing stock change can be accounted for between census 2000 (officially, the date is April $1^{\text {st }}$ ) and August $29^{\text {th }}, 2005$. This allows not only for a comparison of pre- and post-Katrina housing, but also pre-and post-Katrina household populations. ${ }^{4,5,6}$

The Long Form was a self-administered questionnaire containing 115 items regarding sources, constraints, and assessments of Hurricane Katrina relief and recovery as well as basic demographic information, the latter of which used census definitions and conventions in the same manner as the Short Form described earlier. It was approved by the Institutional Review Board (IRB) at the University of Mississippi in the late fall of 2005. Each block in the Long Form sample, had a Control Sheet corresponding to the items found in the Short Form. The Long Form was informally tested and revised nine time before a formal pre-test was done in the field. This field pre-test also allowed the study team to assess and refine protocols and procedures associated with the data collection effort.

As stated earlier, it was administered to a representative sample comprised of 126 targeted blocks of the total of 573 in the Study Area. Seventy-one of these blocks were found to contain habitable housing. Team members went door-todoor handing out questionnaires and arranging with respondents a time to return for the completed questionnaire. A minimum of two callback attempts was made at each housing unit canvassed that potentially was occupied, including damaged permanent units and all temporary units.

The Long Form data were collected January $8^{\text {th }}$ to $15^{\text {th }}$, 2006, with mail-out/mail-back callbacks collected from January $8^{\text {th }}$ to February $15^{\text {th }}$. Four hundred completed Long Forms were obtained from canvassing and callbacks.

The data collected under the NSF SGER study were matched geographically to the zip code areas reported ear- lier. The matches are not exact but the data reported here come from blocks within them and are representative of the zip codes to which they are matched.

The housing unit counts described in this report were taken from the "short form" data. The population estimates found in the census tract files were generated by the "Housing Unit Method," a generally accepted technique used by demographers (Bryan, [27] 2004). The full form of the Housing Unit Method is defined as:

$$
\mathrm{P}=\mathrm{GQ}+(\mathrm{PPH})(\mathrm{H})(\mathrm{OR})
$$

where

$$
\begin{array}{ll}
\mathrm{P} & =\text { Total Population } \\
\mathrm{GQ} & =\text { Population in Groups Quarters } \\
\mathrm{PPH} & =\text { Persons Per Household } \\
\mathrm{H} & =\text { Total Number of Housing Units } \\
\mathrm{OR} & =\text { Occupancy Rate }
\end{array}
$$

Note that $(\mathrm{H})(\mathrm{OR})=$ Total Number of Households and

$$
\text { That }(\mathrm{H})(\mathrm{OR})(\mathrm{PPH})=\text { Population in Households }
$$

The Housing Unit Method (HUM) implemented here was used to estimate the population in households $((\mathrm{H})(\mathrm{OR})$ $(\mathrm{PPH})=$ Household Population $)$. The 2006 counts of housing units and occupied housing units are taken directly from the data collected under the auspices of the NSF SGER study (Short form data) as was the Persons Per Household (Long form data). The 2005 counts of housing units and occupied housing units were developed by combining the counts of destroyed and habitable housing found in the NSF SGER study to reconstruct the counts of total housing units. The 2000 census provided the occupancy rate and Persons Per Household used to estimate the 2005 household population in conjunction with the reconstructed housing unit counts. The 2000 counts of housing units and occupied housing units were taken from the 2000 census.

The following steps were used to develop the 2007 population data found in Tables $\mathbf{1}$ and $\mathbf{2}$.

Step 1. The 1990 and 2000 populations by age and sex (purchased from PITNEY BOWES MAPINFO) were used to generate "cohort change ratios" (Smith, Tayman, and Swanson, [21] 2001: 127-128) for the population in each of the 12 zip codes.

Step 2. The cohort change ratios (CCRs) were then applied to the 2000 populations (by age and sex) of each of the 12 zip codes to generate 2010 populations by age and sex.

$\underline{\text { Step 3. }}$. The 2010 age and sex data were interpolated to get 2007 age and sex data. The interpolation used a factor of 0.7 to weight the number in a given age group generated for 2010 in the preceding step and a factor of 0.3 to weight the number of people in the same age group found in 2000 . The two weighted numbers were then added together to obtain the interpolation for the age group in question for 2007.

Step 4. Once the interpolated age groups were obtained, the results were either adjusted in accordance with estimates of Katrina's demographic impact as found at the county level by the US Census Bureau or in accordance with the 
block/block group/census tract level in the study funded by the National Science Foundation. The decision about which adjustment factor to use was based on geography.

(Step 4) Census Bureau Adjustment. For those zip codes that did not contain any of the areas covered by the National Science Foundation grant, the US Census Bureau estimates were used as adjustment factors. Zip codes to which this adjustment was applied include 39503 and 39574 in Service Area 1 and 39532, 39573, and 39577 in Service Area 2. The adjustment factor is $(155,817)^{*}(155,817 / 189,601)^{(1 / 6)}$, where 155,817 is the population of Harrison County, as estimated by the US Census Bureau for January $1^{\text {st }}, 2006$, and 189,601 is the population of Harrison County, as counted in census 2000. By taking the ratio of the 2006 population to the 2000 population to the $1 / 6^{\text {th }}$ power, the geometric rate of change is found (.968). Multiplying this rate by the 2006 population of 155,817 yields 150,803 , the estimated population of Harrison County in 2007, as impacted by Hurricane Katrina. This value is then divided by the 2000 population $(189,601)$ to get the ratio of 0.795 , which is multiplied by the population in a given age sex group as found in step 3 .

(Step 4) NSF Adjustment. For those zip codes that did contain areas covered by the National Science Foundation grant, data from the study were used as adjustment factors. Zip codes to which this adjustment was applied include 39501 in Service Area 1 and 39507, 39520, 39525, 39560, and 39571 in Service Area 2. For zip codes 39501, 39507, 39525 , and 39560, data from census tracts 27 and 28 in Harrison County were used. Specifically, it was found that the 2006 household population in the blocks of these two census tracts covered in the NSF study found a population of 4,554 compared to the 2000 population of 5,646 . The number in each age/sex group as found in step 3 was multiplied ratio 4,554/5646 to get the final age-sex numbers for 2007 in these four zip codes. For zip code 39520, data from census tracts 301 and 302 in Hancock County were used. Specifically, it was found that the 2006 household population in the blocks of these two census tracts covered in the NSF study found a population of 2,855 compared to the 2000 population of 2,915 . The number in each age/sex group as found in step 3 was multiplied by the ratio $2,855 / 2,915$ to get the final age-sex numbers for 2007 in zip code 39520 . For zip code 39571, data from census tracts 29 and 30 in Harrison County were used. Specifically, it was found that the 2006 household population in the blocks of these two census tracts covered in the NSF study found a population of 970 compared to the 2000 population of 3,669 . The number in each age/sex group as found in step 3 was multiplied by the ratio $970 / 3,669$ to get the final age-sex numbers for 2007 in zip code 39571 .

\section{Medical Procedure Data and Methods}

The medical procedure data were made available by a provider. The data are not described in detail (e.g., the type of procedure) as a means of preserving the provider's confidentiality. The data are in the form of two sets of monthly time series representing transactions of diagnostic codes (ICD 9) representing candidates presented themselves for a specific medical procedure. The time series data are analyzed using regression models as described in the text and endnotes 1 and 2.

\section{ENDNOTES}

1. The regression model indicated for the data from Facility " $\mathrm{X}$ " (time is the independent variable and the number of cases is the dependent variable) is statistically significant with the following characteristics:

$\left(\mathrm{r}^{2}=.43, \mathrm{p}<.01\right)$

$\mathrm{N}$ of Monthly Cases $=814.00-3.39 *$ time

2. The regression model indicated for the data from Facility "Y" (time is the independent variable and the number of cases is the dependent variable) is statistically significant with the following characteristics:

$\left(\mathrm{r}^{2}=.72, \mathrm{p}<.01\right)$

$\mathrm{N}$ of monthly Cases $=42.72-0.74 *$ time

3. The work supported by the National Science Foundation under Grant No. 0555136 was awarded to the University of Mississippi (D. Swanson (then in the Department of Sociology \& Anthropology at the University of Mississippi), PI; Mark Van Boening (Economics) and Rich Forgette (Political Science), Co-PIs). The Acronym "SGER" stands for "Small Grants for Exploratory Research." Very soon after Katrina struck the Mississippi Gulf Coast, The National Science Foundation issued a call for "SGER" grants to assess its impact.

4. The definition of a housing unit follows that of the Census Bureau's definition as used in the 2000 Decennial Census. However, the Census Bureau has no definition for a "damaged" or "destroyed" housing unit. Given the intent of the study, such a definition was needed. Therefore, a "damaged housing unit was defined as one that had received observable damage, but was still standing and appeared to be structurally sound. For example, a house with a blue tarp for a roof and all of the doors, windows, and interior walls missing was defined as damaged. A destroyed house was one that was either completely gone (e.g., only a slab remained) or sustained structural damage (e.g., supporting beams for the roof had collapsed, a wall was caved in). In cases where it was difficult to distinguish whether a house was damaged or destroyed, it was classified as damaged.

5. The Census Bureau does not distinguish between a temporary and permanent housing unit. Specifically, the Census Bureau defines a housing unit as a shelter intended for 'separate use' by its occupants such that there is independent access to the outside and the shelter is not a group quarters (Swanson and Stephan, [28] 2004: 762). Given the intent of the study, temporary housing units needed to be identified. Therefore, we defined temporary housing units using the following protocol. First, temporary housing units were defined as any non-permanent structure in which people were residing. This included tents, lean-to, campsites, motor vehicles, recreational vehicles, travel trailers, house trailers and mobile homes with their axles and wheels in place. The recreational vehicles, travel trailers, house trailers, and mobile homes classified as temporary housing units generally were on lots next to destroyed or damaged permanent housing units or in parks and usually were connected to power and other utilities. In such cases, even if they were not occupied, we counted them as temporary housing units. If tents, cars, and trucks were encountered that were not occu- 
pied, they were not counted as housing units. Similarly, unoccupied recreational vehicles, travel trailers, house trailers, and mobile homes on sales lots were not counted (These were usually either heavily damaged or destroyed anyway).

6. The household population is comprised of those who live in housing units (as opposed to those who are homeless or living in group quarters - prisons, long-term care hospitals, military barracks, and school and college dormitories (Swanson and Stephan [28], 2004: 762).

\section{ACKNOWLEDGEMENTS}

*The author thanks Mary McGehee and Richard Verdugo for comments and Ken Hodges of CLARITAS and Angelina Tofolli and Tom Exter of Pitney Bowes MAPINFO for assistance in obtaining zip code level data. This material is partly based upon work supported by the National Science Foundation under Grant No. 0555136. Any opinions, findings, and conclusions are those of the author and do not necessarily reflect the views of the National Science Foundation.

\section{REFERENCES}

[1] Kintner H, Swanson D. Estimating vital rates from corporate databases: how long will GM's salaried retirees live? In: Kintner H, Merrick T, Morrison P, Voss P, Eds. Demographics: a casebook for business and government. Santa Monica: RAND: 1994; pp. 265-97.

[2] Lamb V, Siegel J. Health demography. In: Siegel J, Swanson D, Eds. The methods and materials of demography. San Diego: Elsevier Academic Press 2004; pp. 341-70.

[3] Lee RD, Carter L. Modeling and forecasting U.S. mortality. J Am Stat Assoc 1992; 87: 659-75.

[4] Manton K, Stallard E. Medical demography: interaction of disability dynamics and mortality. In: Martin L, Preston S, Eds. Demography of aging. Washington: National Academy Press 1994; pp. 217-78.

[5] Manton K, Stallard E. Recent trends in mortality analysis. Orlando: Academic Press 1984

[6] Murdock S, Hamm R. A demographic analysis of the market for a long-term care facility: a case study in applied demography. In: Kintner H, Merrick T, Morrison P, Voss P, Eds. Demographics: a casebook for business and government. Santa Monica: RAND 1994: pp: 251-64.

[7] Pol L, Thomas R. The demography of health and health care. New York: Plenum 2000.

[8] Pol L, Thomas R. Demography for business decision making. New York: Quorum Books 1997.

[9] Rives NW. Strategic financial planning for hospitals. In: Kintner H, Merrick T, Morrison P, Voss P, Eds. Demographics: a casebook for business and government. Santa Monica: RAND 1994; pp. 251-64.

[10] Stallard E. Demographic issues in longevity risk analysis. J Risk Insur 2006; 73: 575-609.
[11] Thomas R. Society and health: sociology for health professionals. New York: Kluwer Academic 2003.

[12] Vaupel J, Manton K, Stallard E. The impact of heterogeneity in individual frailty on the dynamics of mortality. Demography 1979; 16: 439-54.

[13] World Association for Disaster and Emergency Medicine: [last accessed Jan 2009]. Available from: http://wadem.medicine. wisc.edu

[14] Noji E. Estimating population size in emergencies. Bull World Health Organ 2005; 83: 164.

[15] Smith S. Demography of disaster: population estimates after hurricane andrew. Popul Res Policy Rev 1996; 15: 459-77.

[16] Stone G. Methods for measuring the population after a disaster: household population surveys in post-katrina new orleans, october 2005 - october 2006. In: Murdock S, Swanson DA, Eds. Applied demography in the $21^{\text {st }}$ century. Dordrecht: Springer 2008; pp. 11323 .

[17] Swanson DA. The demographic effects of hurricane katrina on the mississippi gulf coast: an analysis by zipcode. J Mississippi Acad Sci 2008; 53: 213-31.

[18] Swanson DA, Forgette R, Van Boening M, Holley C, Kinnell A. Assessing katrina's demographic and social impacts on the mississippi gulf coast. J Mississippi Acad Sci 2007; 54: 228-42.

[19] Ewing B, Kruse J, Sutter D. Hurricanes and economic research: an introduction to the hurricane katrina symposium. South Econ Rev 2007; 74: 315- 25 .

[20] Asian Disaster Reduction Center. Total disaster risk management: good practices. Kobe 2005; [last accessed Dec 2008] Available from: http://www.adrc.or.jp/publications/TDRM2005/TDRM_ Good_Practices/Index.html

[21] Smith S, Tayman J, Swanson DA. State and local population projections: methodology and analysis. New York; Kluwer Academic/ Plenum 2001.

[22] U. S. Census Bureau. Special population estimates for impacted counties in the gulf coast area 2006; [last accessed Jan 2009]. Available from; [http://www.census.gov/Press-Release/www/2005/ katrina.htm

[23] Cossman R. Hurricane katrina as a natural experiment of "creative destruction'. J Mississippi Acad Sci 2007; 52: 281-5.

[24] Sokura B, Cosby A. The role of information and communication technology (ict) in the resilience of educational institutions in the wake of hurricane katrina. J Mississippi Acad Sci 2007; 52: 24361.

[25] American Association for Public Opinion Research. Standard definitions: final dispositions of case codes and outcome rates for surveys, AAPOR. Lenexa 2000.

[26] Dillman D. Mail and internet surveys: the tailored design method. New York: Wiley 2000.

[27] Bryan T. Population Estimates. In: Siegel J, Swanson DA, Eds. The methods and materials of demography. New York: Elsevier Academic Press 2004; pp. 523-60.

[28] Swanson DA, Stephan GE. Glossary. In: Siegel J, Swanson DA Eds. The methods and materials of demography. New York: Elsevier Academic Press 2004; pp.751-78. 